\title{
O PAPEL DA EXTENSÃO UNIVERSITÁRIA E SUA CONTRIBUIÇÃO PARA A FORMAÇÃO ACADÊMICA SOBRE AS ATIVIDADES CIRCENSES
}

\author{
Teresa Ontañón Barragán \\ Universidade Estadual de Campinas, Campinas, São Paulo, Brasil \\ Gilson Santos Rodrigues \\ Universidade Estadual de Campinas, Campinas, São Paulo, Brasil \\ Gabriel da Costa Spolaor \\ Universidade Estadual de Campinas, Campinas, São Paulo, Brasil \\ Marco Antonio Coelho Bortoleto \\ Universidade Estadual de Campinas, Campinas, São Paulo, Brasil
}

\begin{abstract}
Resumo
A extensão universitária é reconhecida como um dos três pilares da Educação Superior Brasileira, representando um importante espaço de formação e de aproximação entre a universidade e a sociedade. Este artigo objetiva discutir o papel educativo e formativo da extensão através do projeto "Atividades Circenses para Crianças", oferecido semestralmente na Faculdade de Educação Física da Unicamp desde 2006. Por meio do relato de experiência deste projeto, vemos que ele vem contribuindo para um maior debate sobre a educação artístico-corporal e, consequentemente, para o fomento da criatividade, expressividade e ludicidade tanto para os participantes, como entre os graduandos dessa faculdade, produzindo, assim, maior coerência e coesão entre as práticas de ensino, pesquisa e extensão nesse âmbito. Palavras-chave: Extensão Universitária - Comunitária; Circo; Educação Física; Educação Estética.
\end{abstract}

\section{O papel da Extensão Universitária na formação dos professores de educação física}

Durante a última década, especialmente a partir do crescimento dos programas de pósgraduação no Brasil (TANI, 2000; KOKUBUN, 2003; ROSA; LETA, 2011; BRASIL, 2013), assistimos a uma hipervalorização da pesquisa e da produção acadêmica (LOVISOLO, 2007) em detrimento das ações de ensino e extensão (BETTI et al., 2004).

Essa nova configuração, predominante em muitas das Universidades públicas, entre elas a Universidade Estadual de Campinas (Unicamp), tem dificultado a manutenção dos programas de extensão (projetos semestrais, cursos de especialização latu sensu etc.) seja pela pouca valorização dessas atividades, seja pela menor quantidade de recursos financeiros. Apesar dessa realidade, a Faculdade de Educação Física da Unicamp (FEF-Unicamp) tem mantido uma intensa atuação no âmbito da Extensão Universitária e Comunitária.

Desde a sua criação, em 1985, a FEF-Unicamp considera as atividades extensionistas como um dos pilares da formação profissional, da produção do conhecimento e do diálogo com a sociedade, contribuindo dessa forma para a complementação dos estudos realizados no âmbito do Ensino e da Pesquisa. Observa-se, assim, um entendimento de que a Extensão 
potencializa a relação entre a Universidade e outros setores da Sociedade, com vistas a uma atuação profissional transformadora, voltada para os interesses e necessidades da população e implementando o desenvolvimento regional e nacional na área, bem como para a promoção de políticas públicas efetivas.

Ao referir-se especificamente à Extensão Universitária, o documento intitulado "O papel da extensão na trilogia universitária" (FEF-Unicamp, 2014a), disponibilizado pela coordenadoria de extensão da FEF-Unicamp, relembra que o Plano Nacional de Extensão, define a Extensão Universitária como:

O processo educativo, cultural e científico que articula o Ensino e a Pesquisa de forma indissociável e viabiliza a relação transformadora entre Universidade e Sociedade. A extensão é uma via de mão-dupla, com trânsito assegurado à comunidade acadêmica, que encontrará, na sociedade, a oportunidade de elaboração da práxis de um conhecimento acadêmico. (FÓRUM DE PRÓ-REITORES DE EXTENSÃO DAS UNIVERSIDADES PÚBLICAS BRASILEIRAS, 1987 p. 11)

Nesse sentido, é importante salientar que a política nacional de extensão conceitua a Extensão Universitária como "processo educativo, cultural e científico que articula o Ensino e a Pesquisa de forma indissociável e viabiliza a relação transformadora entre a Universidade e a Sociedade" (FÓRUM DE PRÓ-REITORES DE EXTENSÃO DAS UNIVERSIDADES PÚBLICAS BRASILEIRAS, 2007, p. 17). Desta forma, notamos que a FEF-Unicamp possui um importante potencial de oferecimento de atividades de extensão, quer pelos espaços físicos, pela demanda da comunidade universitária, pela competência de seu corpo docente, quer pelo interesse e diversidade de práticas oferecidas aos seus estudantes. Um potencial que se transformou numa tradição ao longo de seus 30 anos e num importante aspecto da formação acadêmica oferecida pela faculdade ao longo de sua história.

Semestralmente, são oferecidos projetos de extensão que reúnem as mais variadas práticas corporais, que atendem a comunidade interna e externa em todas as faixas etárias. Alguns desses cursos também são oferecidos durante o período de férias, ampliando o público que pode vivenciar as atividades ofertadas. Vale destacar que os recursos angariados pelas atividades de Extensão, conforme as normativas da Unicamp e da FEF, são investidos tanto na melhoria da infraestrutura da FEF como para custear despesas dos próprios projetos de extensão.

Ao longo dos últimos 10 anos, percebe-se que o programa de Extensão da FEF cresceu tanto do ponto de vista quantitativo, como qualitativamente. Para ilustrar algumas ações extensionistas desenvolvidas na FEF-Unicamp, destacamos a seguir os cursos e projetos oferecidos no primeiro semestre de 2014, incluindo o número de turmas que foram oferecidas nesse período, o número total de vagas que foram preenchidas e as atividades de cada grupo de práticas:

Tabela 1. Projetos de Extensão Universitária do primeiro semestre de 2014.

\section{CIRCO}

Número de turmas oferecidas: 6 Número total de vagas preenchidas: 118

Atividades: Roda Alemã, Tecido Circense, Trapézio e Atividades Circenses para crianças.

CONDICIONAMENTO FÍSICO

Número de turmas oferecidas: 4 Número total de vagas preenchidas: 202

Atividades: Ginásticas de academia (Step, Jump, G.A.P., Aeróbica etc.)

DANÇA

Número de turmas oferecidas: 10 Número total de vagas preenchidas: 317

Atividades: Dança do ventre, Dança de salão, Dança de rua, Hip-Hop, Balé clássico, Forro, Jazz e Dança

Contemporânea. 


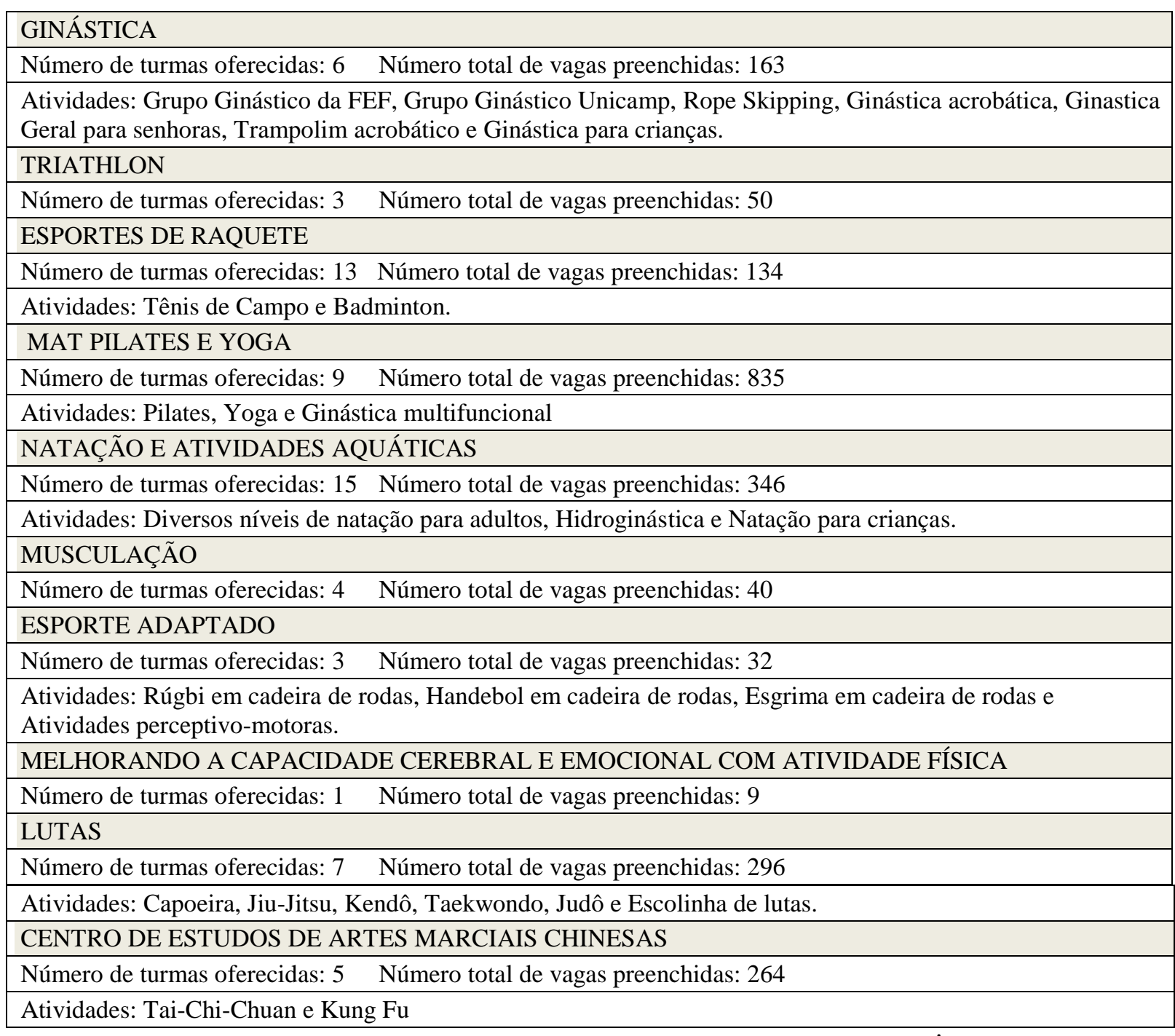

Fonte: CODESP - FEF/Unicamp, julho de 2014.

Segundo os dados acima vemos um total de 3.189 vagas, das quais foram preenchidas 2.766. Constavam ainda 855 nomes nas listas de espera dos projetos que tiveram suas vagas totalmente preenchidas. Esses números são significativos e mostram a dimensão e a diversidade de projetos oferecidos pela FEF na atualidade. Com base nesses dados é possível afirmar que a Extensão Universitária tem permitido à FEF construir um diálogo continuado com a sociedade, bem como complementar e diversificar a formação acadêmica oferecida aos estudantes dessa instituição, muitos dos quais participam como alunos ou como monitores/colaboradores dos projetos, muitas vezes ao longo de vários semestres.

Nesse contexto, trataremos a seguir do Projeto de "Atividades Circenses para Crianças", oferecido semestralmente na FEF-Unicamp desde 2006, visando discutir seu funcionamento, conteúdos e sua contribuição para a formação acadêmica nesse tema, a partir do acompanhamento e da análise das atividades desenvolvidas ao longo do primeiro semestre de 2014, cujo conteúdo foi investigado por meio de uma análise documental do plano de cada uma das aulasi.

\section{Um "picadeiro" dentro da universidade}

É notório que as atividades circenses adquiriram maior visibilidade e protagonismo no cenário nacional a partir do início da década de 2000, abrangendo diversos âmbitos, dentre os 
quais destacamos o do lazer, o social, o terapêutico, o artístico-profissional e o educativo (BORTOLETO; MACHADO, 2003). Em resposta a essa demanda identificamos um importante aumento das pesquisas acadêmicas sobre o circo, muitas das quais analisam aspectos pedagógicos (DUPRAT; BORTOLETO, 2007; DUPRAT; PEREZ GALLARDO, 2010; ONTAÑÓN; BORTOLETO; SILVA, 2013; ONTAÑÓN; BORTOLETO, 2014).

A Universidade e, particularmente, a Extensão Universitária têm se destacado como um terreno fértil para o desenvolvimento das atividades circenses, como revelam os estudos de Abrahão (2011) e Tiaen (2013), por exemplo. Em geral, essas experiências se mostram coerentes com o modelo de Extensão Universitária adotado pela FEF - Unicamp acima descrita e com os propósitos pretendidos no projeto em análise.

A nova configuração histórica de produção da linguagem circense (SILVA, 2008), as mudanças e transformações que ocorreram com o novo currículo da FEF-Unicamp a partir de 2006, e a ação do Grupo de Estudo e Pesquisa das Artes Circenses (Circus) permitiram as condições necessárias para incluir as atividades circenses como um projeto de extensão nessa instituição. De fato, na própria apresentação pública do Circus, a extensão aparece como uma das prioridades do grupo:

Formado em fevereiro de 2006 e certificado pela Unicamp junto ao CNPQ, o Grupo Circus vem realizando na FEF-Unicamp estudos, pesquisas, projetos de extensão universitária, eventos, projetos de iniciação científica, orientações de mestrado e doutorado relacionados com as atividades circenses e suas relações com a Educação Física. Este coletivo também apoiou eventos externos, consultorias a cursos, eventos e pesquisas, além de dar suporte aos fabricantes de materiais circenses e projetos socioculturais neste setor. (CIRCUS, 2014).

Nesse mesmo período, foi criada a disciplina eletiva (optativa) "EF962 - Atividades Circenses e Educação Física", que tem como objetivo apresentar aos estudantes a diversidade das atividades circenses e suas múltiplas possibilidades pedagógicas na área da Educação Física. A disciplina recebe a participação semestral de muitos dos membros do grupo CIRCUS (formado por pesquisadores, artistas e profissionais do Circo) oferecendo experiências diferentes aos alunos matriculados e abrindo novas possibilidades de atuação profissional, como destacam Bortoleto e Celante (2011).

Foi então, visando completar a tríade acadêmica - ensino, pesquisa, extensão -, que foi criado o Projeto de Extensão de Circo, que inclui diferentes "turmas" (especialidades), dentre as quais destacamos: Encontro Aberto de Circo (2006-2012), Tecido Circense; Trapézio Circense; Lira; Roda Alemã; e Atividades Circenses para Crianças.

Essa última turma, objeto de análise no presente artigo, é apresentada na página web da FEF-Unicamp da seguinte forma:

O projeto Atividades Circenses pretende oferecer aulas práticas-vivenciais de circo para crianças de 8 a 12 anos com ou sem experiência anterior. Nestas aulas serão trabalhados os fundamentos dos malabares, equilíbrios sobre objetos, equilíbrios de objetos, aéreos e acrobacias (Circus - FEF-Unicamp, 2014).

O projeto de circo oferece semestralmente entre seis e oito turmas, com aproximadamente 140 vagas, sendo 20 delas para a turma de Atividades Circenses para Crianças. Nesse período foram 17 oferecimentos (grupos/semestre), com um crescente interesse da comunidade interna e externa à Unicamp. De fato, a procura tem superado o número de vagas, porém, considerando as condições operacionais (monitores, material, espaço etc.), esse número permanece sem ampliação, embora em anos anteriores tenha havido registros de grupos com até 30 crianças participantes (CIRCUS, 2014).

Desse modo, o projeto teve mais de 350 participantes, bem como o envolvimento de 
mais de uma dezena de monitores, dentre os que vários deles adotaram o ensino do circo em escolas, academias e outros espaços educativos após a experiência no projeto. Vale ressaltar que é frequente que as crianças matriculadas repitam o curso por vários semestres, o que indica uma continuidade da participação dos alunos, bom interesse pelas atividades oferecidas e um significativo desafio pedagógico para manter as atividades motivadoras para iniciantes e também para as mais experientes. O mesmo podemos dizer dos monitores, que frequentemente optam por permanecer diversos semestres e, assim, podem aprofundar-se no tema.

Considerando as normas da FEF - Unicamp, os monitores e colaboradores precisam ser alunos regularmente matriculados na universidade; além disso, por um critério do coordenador, recomenda-se que participem das reuniões regulares do grupo Circus e que, preferencialmente, tenham cursado a disciplina EF962, buscando, desse modo, conhecer os princípios pedagógicos e didáticos que norteiam o projeto.

De um modo geral, o projeto visa apresentar as atividades circenses aos alunos promovendo um debate sobre a diversidade cultural e artística, inclusão, autonomia, criatividade, expressão corporal e sociabilidade entre as crianças, sempre a partir de uma proposta lúdica, de modo a oferecer a elas vivências e conhecimentos das diferentes modalidades circenses, dentre as que podemos destacar: manipulação de objetos (malabares com distintos objetos), equilíbrio de objetos (pratos e bolas), equilíbrio sobre objetos (rolarola, perna de pau, arame fixo, bola etc.), acrobacias, palhaço, aéreos (tecido, trapézio etc.). Com isso, buscamos oferecer uma visão ampla e contextualizada do Circo, como sugerem Invernó (2003), Duprat e Bortoleto (2007) ou Ontañón et al. (2013).

Dessa forma, as aulas são organizadas de modo a acentuar nas crianças a curiosidade e a descoberta a partir dos princípios pedagógicos desenvolvidos pelos pesquisadores do Circus e descritos por Ontañón et al. (2013), a saber:

- A busca por uma pedagogia das atividades circenses que procure adequar os conhecimentos das diferentes práticas circenses ao espaço de prática, desenvolvendo aquelas que mais bem se ajustarem aos objetivos educativos, a partir de um processo metodológico diverso que oportunize uma visão ampliada sobre a arte circense (DUPRAT; BORTOLETO, 2007);

- O fomento de uma "cultura de segurança" entre os alunos ${ }^{\mathrm{ii}}$, que possibilite o entendimento do risco como elemento estético do Circo e permita que as situações pedagógicas propostas sejam seguras, controlando o risco inerente a elas e dando lugar para a permanência do risco simbólico e seu atrativo estético (WALLON, 2008). Nosso trabalho, então, consiste em estudar as atividades que serão propostas e desenvolver mecanismos e procedimento que permitam evitar possíveis acidentes, de modo que os alunos vivenciem o projeto de forma segura;

- Fazer com que os alunos participem ativamente do processo pedagógico, compreendendo suas responsabilidades, contribuindo na elaboração, execução e avaliação das atividades propostas, tomando decisões (como a escolha de temas para as apresentações). Essa consciência deve ser construída através da prática, no fazer cotidiano, pressupondo a colaboração de todos os envolvidos (BORTOLETO et al., 2010). Um exemplo disso se deu na apresentação dos alunos em homenagem ao artista Ramon Ferroni, que surgiu da própria vontade dos alunos após uma aula temática ministrada por Daniel Lopes ${ }^{\mathrm{iii}}$; o que nos leva ao seguinte ponto;

- Destacar a importância do processo histórico de construção dos saberes e práticas circenses, considerando o circo como "uma escola única e permanente" (SILVA, 2008) e que possui distintas formas de tratar e compreender sua produção artística. Desse modo, as aulas incluem questões histórico-conceituais, permitindo a inclusão dos cobiçados conteúdos transversais bem como o trato de valores humanos com foco nas especificidades do Circo, usando recursos disponíveis dos pesquisadores e adaptando estes à linguagem infantil, como foi feito, 
por exemplo, com a pesquisa desenvolvida por Lopes (2010), que resultou no Documentário Don Ramon, já mencionado (LOPES E SILVA, 2009);

- Reconhecer a importância do jogo no processo pedagógico, tratando de criar situações lúdicas como forma introdutória das atividades circenses (PRODÓCIMO; PINHEIRO; BORTOLETO, 2010) para poder cativar e aproximar todos os alunos a este conhecimento que, para muitos, ainda é considerado um saber simbólico (ainda não vivenciado). Utilizar os elementos constitutivos do jogo (espontaneidade, afetividade, integração, entusiasmo, motivação, regras, criatividade etc.) para a criação de um ambiente favorável ao ensino;

- Construção artesanal do material pedagógico: em todos os semestres realizamos no mínimo uma aula na qual os alunos têm a oportunidade de criar seu próprio material circense, isso permite, além de ensinar como construir o próprio material a um custo baixo, fomentar a criatividade e aprender a valorizar e cuidar do material. Muitos dos objetos e equipamentos circenses, sobretudo os malabarísticos, podem ser facilmente construídos de uma forma barata, apenas com a reciclagem de materiais como bexigas, papelão, jornais, arroz etc. Materiais como esses, que muitas vezes são pouco utilizados, podem ser transformados em bolas de malabares ou até mesmo em claves. Por outro lado, a experiência de produzir, explorar e ter os próprios materiais circenses é um exercício importante para as crianças, pois possibilita a apropriação de um saber, a "cultura do fazer" como alternativa à "cultura do comprar", e uma educação da responsabilidade com seus materiais. Além disso, o fato de os alunos criarem o seu próprio material os aproxima da atividade proposta, fazendo com que aumentem o interesse pela prática (Imagem 1);

- Reconhecer o Circo como uma linguagem artística e como um importante instrumento para o fomento da expressividade, potencializando uma educação criativa que elogie as diferenças dos alunos ao invés de tentar padronizar comportamentos. Essas atividades procuram uma aproximação às artes e ao fomento da criatividade e expressividade dos alunos;

Por outro lado, no sentido de oferecer uma pedagogia das atividades (alunos construindo bolinhas de malabares). Fonte: circenses que leve em consideração a Acervo dos autores.

diversidade do circo, buscamos, ao longo das aulas, propor vivências sobre distintas modalidades circenses, a partir da adaptação das classificações propostas por Duprat e Bortoleto (2007) e Invernó (2003). Desse modo, dividimos os conteúdos em seis "famílias" ou categorias de modalidades:

\section{Manipulação de objetos / Malabarismos:}

Realizamos jogos, brincadeiras e atividades com jornais (BORTOLETO et al., 2010), lenços e materiais típicos do circo (bolas, aros, claves, caixas, diabolôs etc.) (BORTOLETO et al, 2008; BORTOLETO; PINHEIRO; PRODÓCIMO, 2011);

\section{Acrobacias:}

Individual: Atendendo ao desenvolvimento do próprio aluno, são propostos exercícios como parada de mãos, cambalhota, roda lateral etc.

Coletiva: são realizadas figuras acrobáticas simples, em duplas, trios ou mais pessoas, 
buscando a colaboração entre alunos e o companheirismo.

\section{Equilíbrios sobre objetos ou atividades funambulescas:}

Realização de atividades que desenvolvam o equilíbrio corporal nos alunos, partindo desde equilíbrios simples até aos mais complicados, utilizando o espaço e materiais disponíveis. Incluindo atividades de perna de pau, monociclo e bola de equilíbrio, partindo da apresentação dos elementos e exercícios de iniciação, fomentando a ajuda entre companheiros e a colaboração para conseguir a maior estabilidade possível e assim poder avançar até exercícios de maior dificuldade que permitam jogos e outras atividades usando este elemento;

\section{Palhaço / Ator circense / Interpretação e Dramaturgia circense:}

Atividades relacionadas com a expressão corporal, mímica e aproximação ao típico palhaço do Circo. O trabalho é aproximar os alunos ao mundo do palhaço mediante exercícios lúdicos de expressão, dando a conhecer os diferentes tipos de palhaços, a maquiagem utilizada, "gags", atividades cômicas etc.;

\section{Aéreos:}

Atividades que acontecem em aparelhos como trapézio, tecido e lira, por exemplo, que permitem a experiência da motricidade num espaço vertical e distante do solo;

\section{Outras práticas:}

Nesse último grupo de atividades oferecemos práticas que fazem parte da cultura do Circo, mas que, por apresentar maior risco à integridade dos alunos, requerem adaptações. Assim, modalidades circenses que exacerbam deformações corporais (freakismo), que utilizam materiais perfurantes (faquirismo), a manipulação de fogo (pirofagia) (DUPRAT; BORTOLETO, 2007), atividades que passam a contradizer valores educativos (mágica, ilusionismo, prestidigitação), e que apresentam grandes riscos à integridade física (globo da morte, homem-bala, atirador de facas etc.) são trabalhadas por meio da observação (vídeos, apresentações etc.), e, em alguns casos, vivenciadas por meio de jogos simbólicos, baseados na lógica interna das práticas e que preservam o risco simbólico da prática, mas que eliminam o risco físico (BORTOLETO, 2011 - vide "Atirador de Facas"), como fizemos, por exemplo, em algumas aulas nas quais os alunos vivenciaram a atividade de tranca e antipodismo (manipulando com os pés diversos objetos que não eram perigosos para os alunos e oferecendo a eles a oportunidade de conhecer o material de prática real de um artista de circo).

Outro detalhe importante do projeto é o fato de recebermos professores convidados para realizar algumas aulas especiais ou pequenas apresentações artísticas, entre outras atividades, ao longo do semestre. Como exemplo, podemos mencionar uma oficina de maquiagem facial circense, uma aula com palhaços e uma apresentação com

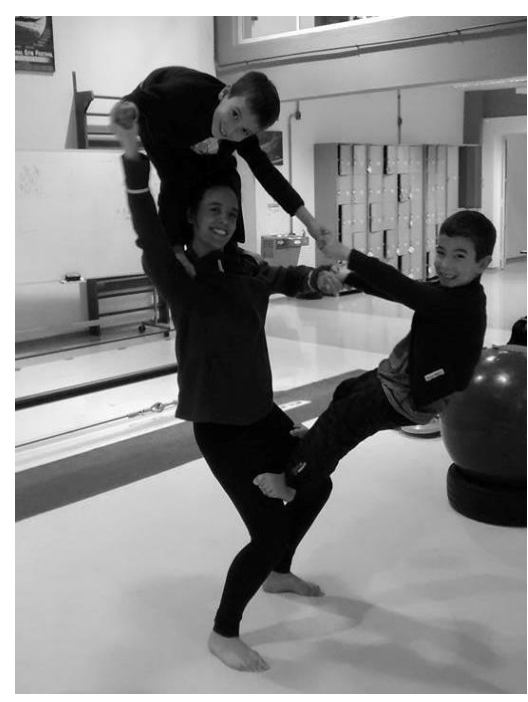

Imagem 2. Aula Especial com os pais (figura acrobática da mãe com seus dois filhos). Fonte: Acervo dos autores. acrobatas profissionais. Essas experiências, em seu 
conjunto, possibilitam às crianças uma maior aproximação ao universo circense bem como a oportunidade de estabelecer contato com profissionais da área, possibilitando a discussão de certos preconceitos que possam existir sobre o Circo e seus artistas.

Em outra aula especial que faz parte do cronograma semestral, realizada normalmente no final do semestre, as crianças convidam familiares (especialmente pais ou responsáveis) e amigos a participarem de uma vivência de atividades circenses. A proposta desta aula é que os alunos tenham a oportunidade de praticar as atividades desenvolvidas ao longo do curso exercendo uma "docência tutorada" e podendo "ensinar" parte do que foi aprendido no projeto - e que tenham ademais a oportunidade de vivenciar as atividades circenses de uma maneira lúdica na companhia de familiares entes queridos. Nossa experiência revela que esse tem sido um momento único, do qual tanto crianças quanto adultos desfrutam e participam com prazer (Imagem 2).

Apesar de trabalharmos diversas modalidades circenses a cada semestre, seguindo os princípios pedagógicos mencionados, damos um destaque maior para um elemento específico do Circo. A título de exemplo, no primeiro semestre de 2014 (março-julho; 15 encontros) o tema norteador foi a "história do circo", e o objetivo foi fazer com que as crianças tivessem noção da importância desta história e conhecessem alguns fatos e dados históricos que hoje fazem com que apreciemos e vivenciemos o circo como o conhecemos.

Para tal fim, após realizar algumas aulas introdutórias das diversas modalidades circenses, realizamos cinco aulas temáticas sobre a história do circo.

Na primeira aula, utilizamos alguns desenhos e o livro "A grande história do circo em quadrinhos" (BHAKTA, 2010), que adapta o conteúdo circense à linguagem infantil e ilustra o texto com vasta riqueza de imagens, facilitando assim o diálogo com as crianças. Nessa mesma aula escolhemos alguns momentos importantes e realizamos junto às crianças várias brincadeiras relacionadas aos saltimbancos, aos funâmbulos, ao circo de lona (com um paraquedas), ao circo com cavalos e outros animais, etc.

Devido à história do circo ser muito ampla, decidimos (orientados pela professora e historiadora do circo Dra. Erminia Silva, co-coordenadora do Circus), selecionar três momentos específicos dessa história, sendo esses: as apresentações nas ruas e feiras dos saltimbancos na Idade Média; a contribuição do coronel Philip Astley e a criação do primeiro espetáculo de circo fechado, o Astley's Amphitheatre em 1768; e, por último, a projeção do circo itinerante de lona no modelo de produção do conhecimento denominado "circo-família", que vem frequentando vilarejos e cidades no Brasil desde o século XIX (SILVA, 2008).

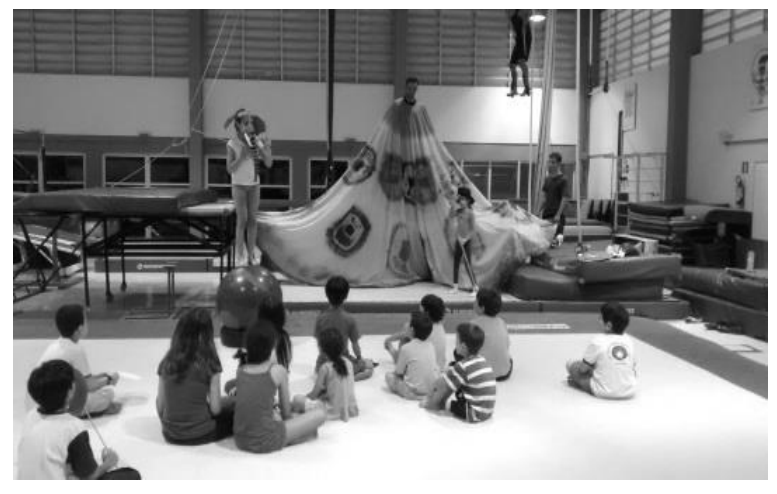

Imagem 3 - Aula com o tema "A história do circo: o circo de lona". Fonte: Acervo dos autores.

Dedicamos uma aula para cada um dos três momentos mencionados, realizando atividades de perna de pau, acrobacia e malabares para os saltimbancos, brincadeiras simulando cavalos, cavaleiros e coronéis ao ritmo dos tambores militares para o circo do Astley's Anphitheatre, e para o circo de lona, atividades com o paraquedas simulando a montagem da lona (Imagem 3), palhaços, domadores de animais e outras atividades. Sendo que, no início de cada aula, aproveitávamos para contar a história de cada momento para as crianças, deixando correr sua imaginação e provocando diversas perguntas e debates, como por exemplo, a presença dos animais nos circos, ou a importância de todos os membros da família no universo circense. 
Por último, para fechar as aulas sobre a história do circo, realizamos, como em todos os semestres, uma gincana circense, composta por diversos jogos relacionados com as atividades circenses. Num primeiro momento as crianças foram divididas em grupos ou "famílias circenses", (fazendo relação com o circo-família); a primeira prova consistiu em inventar um nome e uma apresentação da família, contando criatividade, participação e expressão. A segunda parte da gincana foi composta por quatro jogos (estações), a saber: Rola-cesto, jogo das argolas, o atirador de facas e o diabolôcesto (todos eles descritos detalhadamente em BORTOLETO et al., 2010 nas páginas 85-86, 135-136, 148-149, 61-62).

A última prova da gincana, chamada "Quizz Circense", foi um concurso de perguntas e respostas no qual elaboramos questões a partir dos conteúdos relacionados à história do circo tratada ao longo do semestre, de maneira que cada grupo poderia complementar a resposta do outro (Imagem 4).

O resultado foi excelente, já que as crianças demonstraram que tinham guardado todas as informações relacionadas. $\mathrm{O}$ fato também foi comprovado a partir de conversas com os pais e mães dos alunos, que comentaram como seus filhos não autores.

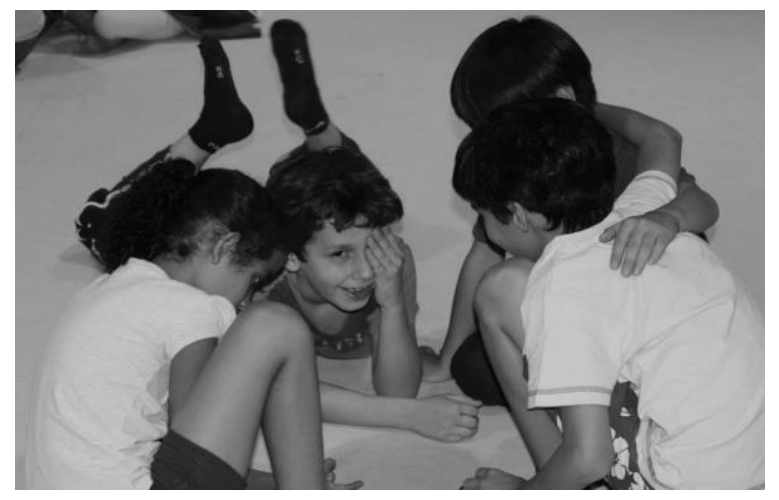

Imagem 4. Aula da gincana circense (alunos se reunem para responder o quiz); Fonte: Acervo dos paravam de falar sobre o tal "coronel Astley" que apresentava números com cavalos no circo.

Para finalizar o semestre, realizamos uma pequena apresentação no XVI Festival Interno da FEF. Nesse evento se apresentaram tanto alunos dos projetos de extensão, como artistas e grupos externos à Faculdade. Foi uma oportunidade para que as crianças apresentassem parte das atividades que aprenderam durante o semestre e vivenciarem uma parte importante do que significa praticar a arte circense, do ponto de vista do "espetáculo", em outras palavras: elas puderam vivenciar o "frio na barriga" antes da apresentação para um grande público (aproximadamente 600 pessoas) e sentir a satisfação dos aplausos ao final, parte fundamental da educação artística-estética que o circo pode oferecer, como debate Hotier (2003).

\section{Considerações finais}

O curso de Educação Física tem várias especificidades que dificilmente se encontram em outros cursos superiores. $\mathrm{O}$ futuro profissional dessa área deve qualificar-se para assumir aulas práticas, independente do contexto de sua atuação. Contudo, as diversas oportunidades que os estudantes têm de poder vivenciar a prática docente, durante a sua formação, são muitas vezes negligenciadas. Os estágios, por exemplo, visam garantir esse aprendizado, mas com frequência, também não são cumpridos com seriedade, atenção e dedicação adequadas. Assim, observamos frequentemente estudantes que retornam à universidade para cursos de formação continuada, buscando conhecimentos que poderiam ter sido obtidos ao longo de sua formação inicial.

Desse modo, a possibilidade oferecida aos estudantes da FEF-Unicamp de poderem atuar junto aos projetos de extensão (que não os isenta dos estágios obrigatórios, mas sim complementa sua formação como docente), torna-se uma grande possibilidade de aprendizagem em situação real de aula, nesse caso, supervisionada e orientada por um projeto consolidado e coerente com a pesquisa do Circus e a disciplina EF962, o que, em nossa opinião, confere ainda mais significância à experiência. 
Essa oportunidade proporciona ademais uma formação especializada numa área incipiente e muito promissora (ONTAÑÓN; DUPRAT; BORTOLETO, 2012), somando-se à imensa variedade de atividades ofertadas pela faculdade. Um conhecimento ainda pouco presente nos cursos superiores e que destaca o currículo dos estudantes perante seus pares.

Nesse sentido, entendemos que o trabalho desenvolvido dentro da extensão da FEF-Unicamp, além de propiciar a oportunidade de formação profissional para os alunos da faculdade, tem conseguido cumprir com o seu papel comunitário, frente ao oferecimento de atividades diversificadas para a sociedade, tornando o processo de "transferência" dos conhecimentos produzidos na universidade mais rápido e efetivo.

No que se refere especificamente aos saberes próprios das atividades circenses, notamos que o interesse e a procura por essas atividades são cada vez maiores, e os estudantes que participaram como monitores nesse projeto frequentemente são procurados por escolas, empresas de lazer ou academias que pretendem incorporar essas práticas em suas atividades, uma vez que ainda é escassa a oferta de profissionais qualificados nessa área. As Atividades Circenses, portanto, se constituem num campo profícuo de atuação profissional para o egresso de Educação Física.

Atentando para os alunos do projeto, já observamos que os princípios pedagógicos que balizam as aulas permitem vivências que contribuem para educação corporal, artística e estética, conforme mencionado por Bortoleto (2011).

Sabemos também que o número de crianças que tem acesso ao curso ainda é reduzido, considerando a demanda atual, assim como a quantidade de crianças que não têm acesso a este tipo de prática. Esperamos, assim, inspirar iniciativas similares em outras universidades de modo que as atividades circenses possam formar parte da realidade de mais graduandos de Educação Física e de muitas outras crianças.

\title{
THE ROLE OF UNIVERSITY EXTENSION AND ITS CONTRIBUTION TO ACADEMIC TRAINING IN CIRCUS ACTIVITIES
}

\begin{abstract}
The university extension is recognized as one of the three pillars of the Brazilian Higher Education, this is an important area of training and an approach between University and the community. This article aims to discuss the educational and formative role of university extension through the project called "Circus Activities for Children", offered every semester at the Faculty of Physical Education of Unicamp since 2006. Through the experience report of this project, we see that it has contributed for the debate in corporal and artistic education and, consequently, encouraging creativity, expressiveness and playfulness for both, participants and graduate students of this faculty, producing a better coherence and cohesion between teaching practices and extension in this area.
\end{abstract}

Keywords: University Comunity Activities. Circus. Physical Education. Aesthetic Education.

\section{EL PAPEL DE LA EXTENSIÓN UNIVERSITARIA Y SU CONTRIBUCIÓN PARA LA FORMACIÓN ACADÉMICA SOBRE LAS ACTIVIDADES CIRCENSES}

\begin{abstract}
Resumen
La extensión universitaria es reconocida como uno de los tres pilares de la Educación Superior Brasileña, representando un importante espacio de formación y de aproximación entre la universidad y la sociedad. Este artículo objetiva discutir el papel educativo y formativo de la extensión a través del proyecto "Actividades Circenses para Niños", ofrecido
\end{abstract}


semestralmente en la Facultad de Educación Física de la Unicamp desde 2006. Mediante el relato de experiencia de este proyecto, vemos como este viene contribuyendo para un mayor debate sobre la educación artístico-corporal y, consecuentemente, para el fomento de la creatividad, expresividad y ludicidad tanto para los participantes, como entre los graduandos de esta facultad, produciendo, así, mayor coherencia y cohesión entre las prácticas de enseñanza, investigación y extensión en este ámbito.

Palabras clave: Extensión Universitaria - Comunitaria. Circo. Educación Física. Educación Estética.

\section{Referências}

ABRAHÃO, S. R. Valoración de las actividades circenses en la formación del profesorado de educación física: una propuesta para la transformación social en la escuela. 2011. Tese (Doutorado en Activitat Física, Educación Física) - Facultat de Formació del Professorat, Universidad de Barcelona, Barcelona,2011.

BETTI, M. et al. A avaliação da Educação Física em debate: implicações para a subárea pedagógica e sociocultural. Revista Brasileira de Pós-Graduação, v. 1, n. 2, p. 183-194, nov. 2004. Disponível em: 〈http://ojs.rbpg.capes.gov.br/ index.php/rbpg/article/view/48/45> Acesso em: 23 dez. 2014.

BHAKTA, D. A grande História do Circo em quadrinhos. Grupo Rosa dos Ventos: Presidente Prudente, 2010.

BORTOLETO, M. A. C. (Org.). Introdução à pedagogia das atividades circenses. Jundiaí, SP: Fontoura, 2008.

BORTOLETO, M. A. C. (Org.). Introdução à pedagogia das atividades circenses. v. 2. Jundiaí: Fontoura, 2010.

BORTOLETO, M. A. C. Atividades circenses: notas sobre a pedagogia da educação corporal e estética. Cadernos de Formação RBCE, v.2, n.2, p.43-55, jul. 2011.

BORTOleto, M. A. C.; CELANTE, A. R. O ensino das atividades circenses no curso de Educação Física: experiências na universidade pública e privada. In: PEREIRA, E. M. A.; CELANI, G.; GRASSI-KASSISSE, D. M. (Org.). Inovações Curriculares: experiências no Ensino Superior. Campinas: FE/Unicamp, p. 178-190, 2011.

BORTOLETO, M. A. C.; PINHEIRO, P. H. G.; PRODÓCIMO, E. Jogando com o circo. Várzea Paulista, SP: Fontoura, 2011.

BORTOLETO, Marco A. C.; MACHADO, Gustavo. Reflexões sobre o Circo e a Educação Física. Santo André: Revista Corpoconsciência, v. 2, n. 12, p. 36-69, 2003.

BRASIL. Constituição da República Federativa do Brasil. Brasília: 1988. Senado Federal. Lei de Diretrizes e Bases da Educação Nacional: n $^{0}$ 9394/96. Brasília: 1996. 
Ministério da Educação. Coordenação de Comunicação Social da Capes - Fundação Capes. Resultados da Avaliação da Capes revelam que pós-graduação teve crescimento de $23 \%$ no triênio. 2013.

CIRCUS. Grupo de Estudo e Pesquisa das Artes Circenses. Disponível em: <http://www.fef.unicamp.br/fef/posgraduacao/gruposdepesquisa/circus/apresentacao>.

Acesso em: 27 jun. 2014.

DUPRAT, R. M.; BORTOLETO, M. A. C. Educação Física escolar: pedagogia e didática das atividades circenses. Revista Brasileira de Ciências do Esporte, Campinas, v. 28, n. 2, p. 171-189, jan. 2007.

DUPRAT, R. M.; PEREZ GALLARDO, J. S. Artes circenses no âmbito escolar. 1. ed. Ijuí: Unijuí, 2010.

FACULDADE DE EDUCAÇÃO FÍSICA DA UNIVERSIDADE ESTADUAL DE CAMPINAS. Deliberação CONSU-A-013/1992. 1992. Disponível em: <http://www.fef.unicamp.br/fef/extensao>. Acesso em: 14 ago. 2014.

FACULDADE DE EDUCAÇÃO FÍSICA DA UNIVERSIDADE ESTADUAL DE CAMPINAS. Resolução congregação FEF/UNICAMP No 65/07. 2007. Disponível em: <http://www.fef.unicamp.br/fef/extensao/normas>. Acesso em: 15 jul. 2014.

FACULDADE DE EDUCAÇÃO FÍSICA DA UNIVERSIDADE ESTADUAL DE CAMPINAS. Projeto pedagógico dos novos currículos dos cursos de Educação Física: Licenciatura em Educação Física graduação em Educação Física. Universidade Estadual de Campinas - Faculdade de Educação Física. Campinas, 2011. Disponível em: <http://www.fef.unicamp.br/fef/pdf/graduacao/programa/Projeto_pedagogico_2011.pdf>. Acesso em: 19 jun. 2014.

FACULDADE DE EDUCAÇÃO FÍSICA DA UNIVERSIDADE ESTADUAL DE CAMPINAS. Resolução congregação FEF N58/2013. Normas de Utilização dos Espaços físicos: Laboratorio de Ensino, pesquisa e extensão da Faculdade de Educação Física. 2013.

Disponível em: < http://www.fef.unicamp.br/fef/laboratorios/labfef/apresentacao>. Acesso em: 15 jul. 2014.

FACULDADE DE EDUCAÇÃO FÍSICA DA UNIVERSIDADE ESTADUAL DE CAMPINAS. O papel da extensão na trilogia universitária (juntamente com o ensino e a pesquisa, e os seus mecanismos de ação). Disponível em: <http://www.fef.unicamp.br/fef/extensao>. Acesso em: 14 ago. 2014a.

FACULDADE DE EDUCAÇÃO FÍSICA DA UNIVERSIDADE ESTADUAL DE CAMPINAS. Operacionalização normativa dos espaços físicos e equipamentos da FEF/UNICAMP. Disponível em: <http://www.fef.unicamp.br/fef/extensao/normas>. Acesso em: 15 ago. 2014 b.

FACULDADE DE EDUCAÇÃO FÍSICA DA UNIVERSIDADE ESTADUAL DE CAMPINAS. XVI Festival Interno da FEF. Disponível em: <http://www.fef.unicamp.br/fef/node/708 >. Acesso em: 13 ago. 2014c. 
FERREIRA, D.; BORTOLETO, M. A. C.; SILVA, E. Segurança no circo: questão de prioridade. Várzea Paulista, Ed. Fontoura, 2014.

FÓRUM DE PRÓ-REITORES DE EXTENSÃO DAS UNIVERSIDADES PÚBLICAS BRASILEIRAS. Conceito de extensão, institucionalização e financiamento. In. I Encontro de pró-reitores de extensão das universidades públicas brasileiras, 1987. Disponível em: $<$ http://www.renex.org.br/documentos/Encontro-Nacional/1987-I-Encontro-Nacional-doFORPROEX.pdf >. Acesso em: 13 jan. 2016.

FÓRUM DE PRÓ-REITORES DE EXTENSÃO DAS UNIVERSIDADES PÚBLICAS BRASILEIRAS. Extensão Universitária: organização e sistematização. (Org.): Edison José Corrêa. Coordenação Nacional do FORPROEX. - Belo Horizonte: Coopmed, 2007. Disponível em: < http://www.cedaf.ufv.br/dxt/anexos/pagina/arquivos/2358.pdf >. Acesso em: 13 jan. 2016.

HOTIER, H. (Org.). La fonction éducative du cirque. París: L’Harmattan, 2003.

INVERNÓ, J. C.. Circo y educación física, otra forma de aprender. Barcelona: INDE Publicaciones, 2003.

KOKUBUN, E. Pós-graduação em Educação Física no Brasil: Indicadores objetivos dos desafios e das perspectivas. Revista Brasileira de Ciências do Esporte, Campinas, v. 24, n. 2, p. 9-26, jan. 2003.

LOPES, D. C. Don Ramón: Vida e obra nas artes circenses. Campinas: Universidade Estadual de Campinas, Faculdade de Educação Física (FEF) - Trabalho de Conclusão de Curso, 2010.

LOPES, D. C.; SILVA, E. BRAVO RAMÓN! (Documentário), 47 min. Star1Produção: Projeto contemplado com o Prêmio Carequinha - FUNARTE - 2009.

LOVISOLO, H. R. "Levantando o sarrafo ou dando tiro no pé". Critérios de avaliação e Qualis das pós-graduações em Educação Física. Revista Brasileira de Ciências do Esporte, Campinas, v. 29, n. 1, p. 23-33, set. 2007.

ONTAÑÓN, T.; BORTOLETO, M. A. C.; DUPRAT, R. M. Educação Física e Atividades Circenses: O estado da arte. Porto Alegre: Revista Movimento, v.18, n.02, abr.-jun., 2012.

ONTAÑón, T.; BORTOLETO, M. A. C.; SILVA, E. Educación corporal y estética: Las actividades circenses como contenido de la educación física. Madrid: Revista Iberoamericana de Educación, n.62, p. 233-243, 2013.

ONTAÑÓN, T.; BORTOLETO, M. A. C. Todos a la pista: El circo en las clases de educación física. Barcelona: Apunts, 2014.

PRODOCIMO, E.; PINHEIRO, P. H. G.; BORTOLETO, M. A. C. Jogos circenses como recurso pedagógico. In. BORTOLETO, M. A. C. (Org.). Introdução à pedagogia das atividades circenses, v. 2. Várzea Paulista-SP: Fontoura, 2010.

ROSA, S.; LETA, J. Tendências atuais da pesquisa brasileira em Educação Física Parte 2: a 
heterogeneidade epistemológica nos programas de pós-graduação. Revista Brasileira de Educação Física e Esporte, São Paulo, v.25, n.1, p.7-18, jan./mar. 2011.

SILVA, E. Saberes circenses: Ensino/Aprendizagem em movimentos e transformações In. Bortoleto, M. A. C. et al. Introdução à pedagogia das atividades circenses, v.1, Jundiaí SP: Editora Fontoura, 2008.

SILVA, E.; ABREU, L. A. Respeitável público... O circo em cena. Rio de Janeiro: Funarte, 2009.

TANI, G. Os desafios da Pós-Graduação em Educação Física. Revista Brasileira de Ciências do Esporte. V.22.n.1, p.79-90. Set. 2000.

TIAEN, M. S. Atividades circenses na formação continuada do professor de Educação Física. 2013. 132 f. Dissertação (Mestrado em Educação) - Universidade Federal do Mato Grosso do Sul, Corumbá, 2013.

WALlON, E. (Org.). O circo no risco da arte. (Título original: "Le cirque au risque de l'art”). Belo Horizonte: Autêntica, 2008.

Endereço para correspondência:

teonba@gmail.com

Teresa Ontañón Barragán

Universidade Estadual de Campinas,

Faculdade de Educação Física.

Avenida Érico Veríssimo, 701

CEP:13083-851 - Campinas, SP - Brasil.

\footnotetext{
${ }^{\text {i }} \mathrm{O}$ número do Parecer do Comitê de ética é 786.757 - Ressaltamos que os responsáveis dos alunos assinaram o Termo de Consentimento Livre e Esclarecido assim como o Termo de Concessão do uso das imagens que ilustram esse artigo.

ii Cuja importância é destacada por Ferreira, Bortoleto e Silva (2014).

iii Autor de um documentário em formato DVD sobre a vida do artista circense Ramon Ferroni, resultado da pesquisa realizada durante seu trabalho de conclusão de curso (LOPES, 2010).
} 